\begin{tabular}{|c|c|}
\hline BRTTSH MEDICL JOURNAL VOLUME 290 I JUNE 1985 & PRACTICE OBSERVED \\
\hline \multicolumn{2}{|l|}{ Practice Research } \\
\hline \multicolumn{2}{|c|}{ Active approach to recognising asthma in general practice } \\
\hline L J TOOP & \\
\hline 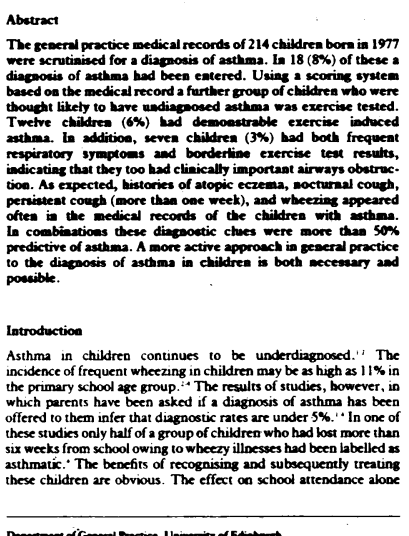 & 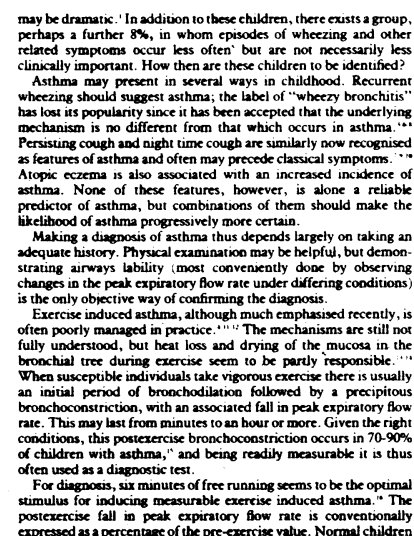 \\
\hline 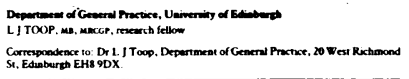 & 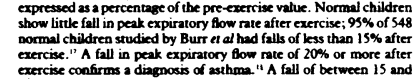 \\
\hline
\end{tabular}

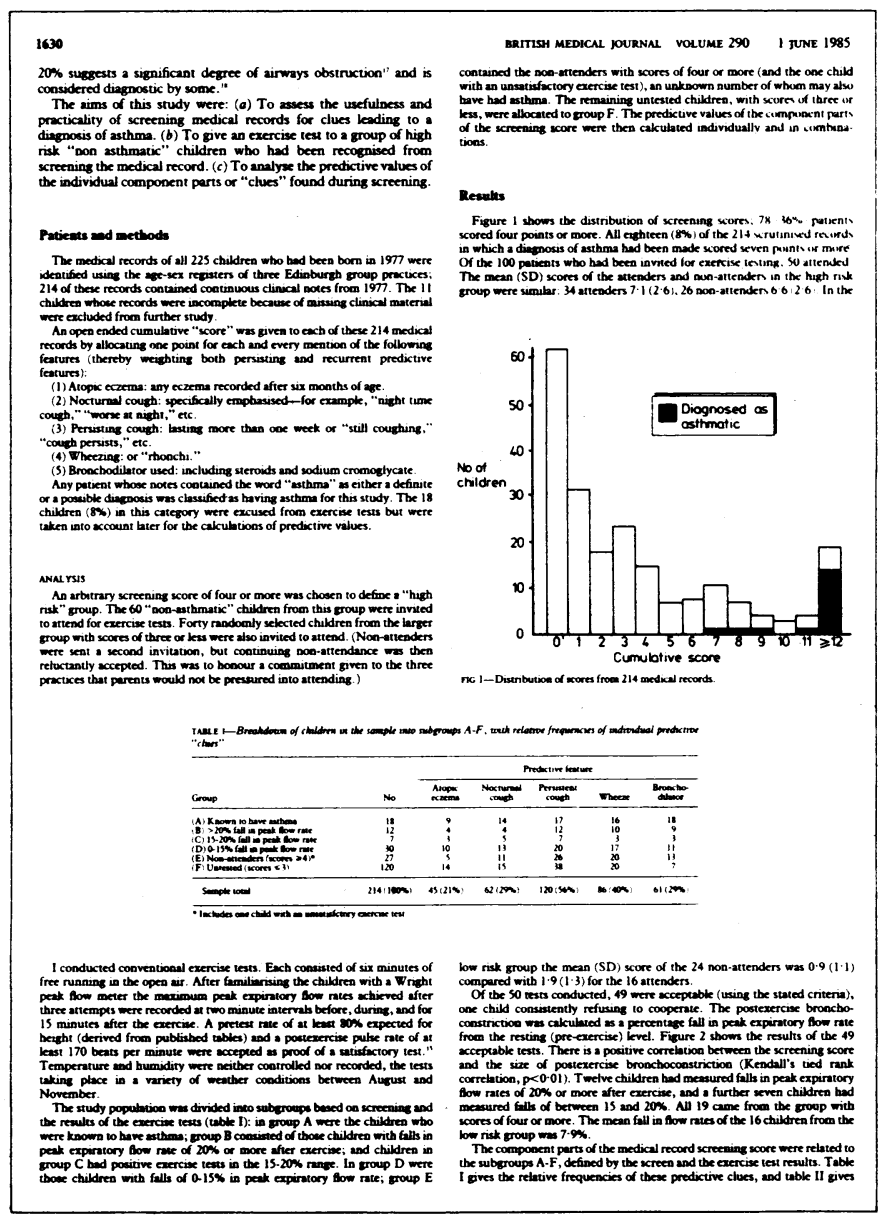

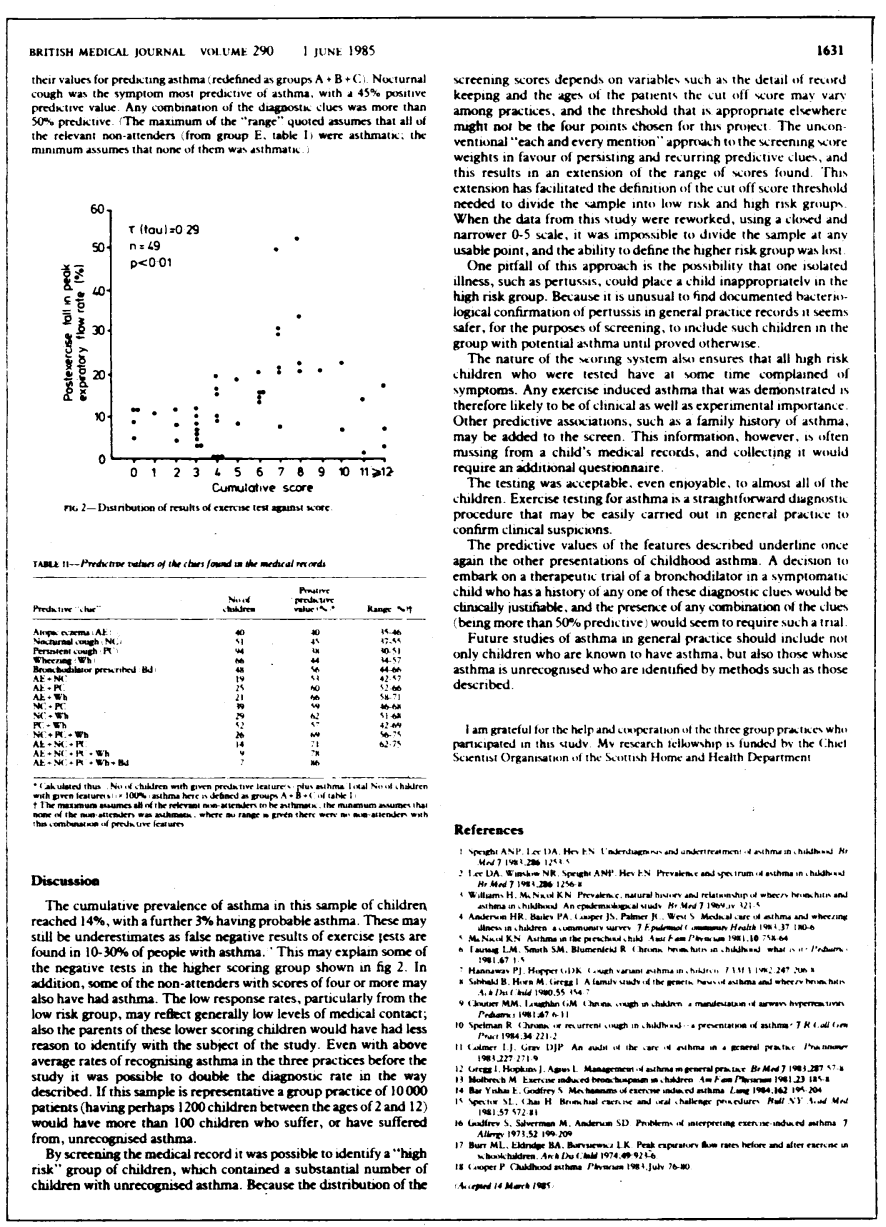

1632

\section{Progress in Practice}

Diabetes care: whose responsibility?

P R w TASKER

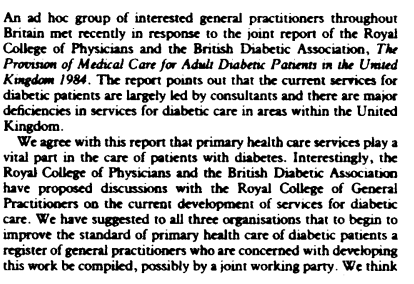

Si)

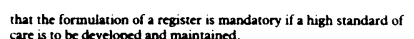

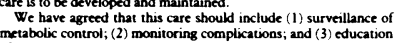

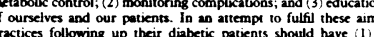

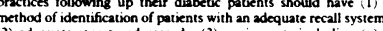

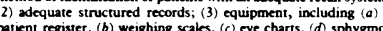

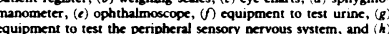

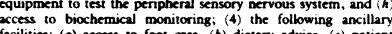

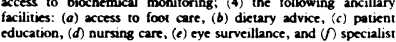

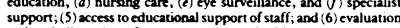

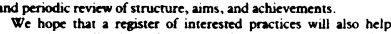
efrectiveness of of

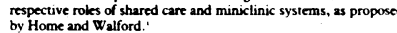

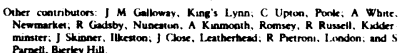

Reference

ind

Muthicutural medicine

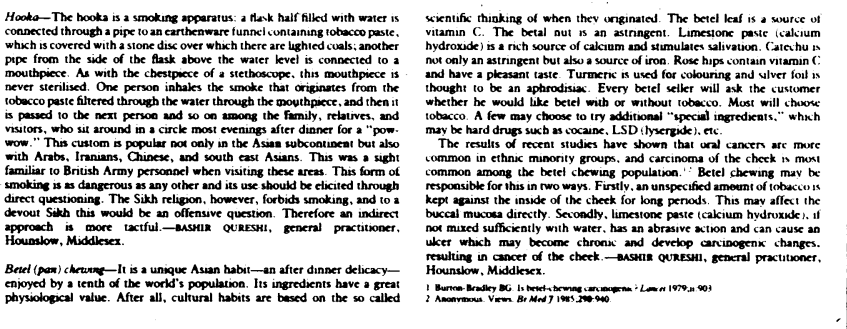

